\title{
Proteomic analysis of prolactinoma cells by immuno-laser capture microdissection combined with online two-dimensional nano-scale liquid chromatography/mass spectrometry
}

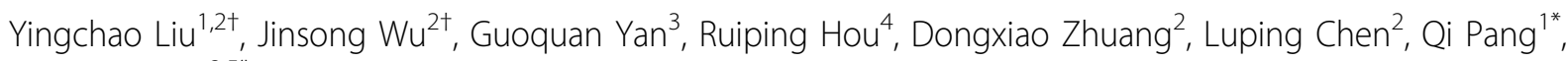
Jianhong $\mathrm{Zhu}^{2,5^{*}}$

\begin{abstract}
Background: Pituitary adenomas, the third most common intracranial tumor, comprise nearly $16.7 \%$ of intracranial neoplasm and $25 \%-44 \%$ of pituitary adenomas are prolactinomas. Prolactinoma represents a complex heterogeneous mixture of cells including prolactin (PRL), endothelial cells, fibroblasts, and other stromal cells, making it difficult to dissect the molecular and cellular mechanisms of prolactin cells in pituitary tumorigenesis through high-throughoutomics analysis. Our newly developed immuno-laser capture microdissection (LCM) method would permit rapid and reliable procurement of prolactin cells from this heterogeneous tissue. Thus, prolactin cell specific molecular events involved in pituitary tumorigenesis and cell signaling can be approached by proteomic analysis.
\end{abstract}

Results: Proteins from immuno-LCM captured prolactin cells were digested; resulting peptides were separated by two dimensional-nanoscale liquid chromatography (2D-nanoLC/MS) and characterized by tandem mass spectrometry. All MS/MS spectrums were analyzed by SEQUEST against the human International Protein Index database and a specific prolactinoma proteome consisting of 2243 proteins was identified. This collection of identified proteins by far represents the largest and the most comprehensive database of proteome for prolactinoma. Category analysis of the proteome revealed a widely unbiased access to various proteins with diverse functional characteristics.

Conclusions: This manuscript described a more comprehensive proteomic profile of prolactinomas compared to other previous published reports. Thanks to the application of immuno-LCM combined with online twodimensional nano-scale liquid chromatography here permitted identification of more proteins and, to our best knowledge, generated the largest prolactinoma proteome. This enlarged proteome would contribute significantly to further understanding of prolactinoma tumorigenesis which is crucial to the management of prolactinomas.

\section{Introduction}

Prolactinomas are the most common pituitary tumors, representing $25 \%-44 \%$ of all pituitary adenoma cases [1]. Although most are pathologically benign and grow slowly, prolactinomas show many symptoms in patients: amenorrhea, galactorrhea and dysgenesis in female

\footnotetext{
* Correspondence: pangqi@sdu.edu.cn; jzhu@fudan.edu.cn

† Contributed equally

${ }^{1}$ Department of Neurosurgery, Shandong Provincial hospital affiliated to Shandong University, Jinan, 250021, China

${ }^{2}$ Shanghai Neurosurgical Center, Department of Neurosurgery, Huashan Hospital, Shanghai Medical College, Fudan University, Shanghai, 200040, China
}

(c) 2010 Liu et al; licensee BioMed Central Ltd. This is an Open Access article distributed under the terms of the Creative Commons Attribution License (http://creativecommons.org/licenses/by/2.0), which permits unrestricted use, distribution, and reproduction in any medium, provided the original work is properly cited.

patients and infertility and erectile dysfunction in male. Moreover, a number of prolactinomas belie their histology by perisellar invasion and postoperative recurrence. Comprehensive molecular dissection of prolactinoma pathogenesis is demanded for further understanding of this kind of tumors. Increasing evidences suggest that characterization at DNA or RNA level alone would not be sufficient to elucidate the mechanisms of this disease as lots of posttranslational modifications exist and pituitary adenoma proteomics would offer an efficient means for a comprehensive analysis of prolactinoma. Desiderio's research on human pituitary adenoma proteome [2-4], plus newly developed proteomics methodologies 
paved a path for further proteomics studies of prolactinomas.

LCM allows the isolation of even single cell and immunohistochemistry (IHC) staining could help to distinguish specific cell populations, thus, employment of immuno-LCM could pick up certain cell populations with specific immuno-phenotype from complex tissues according to their antigen expression to ameliorate the problem of tissue heterogeneity in proteomic research $[5,6]$.

Two-dimensional gel electrophoresis (2-DE) separates mixture of proteins by their isoelectric point (pI) and molecular weight (MW), producing a high-resolution protein map from which protein spots can be processed individually [7]. While 2-DE serves as a powerful separation tool, shotgun proteomics combining LC-MS/MS have emerged as a technique of choice for large-scale protein studies due to its superior throughput and sensitivity [8].

In a typical shotgun proteomics experiment, a complex protein sample is digested into peptides followed by separation by $2 \mathrm{D}$-nanoLC/MS, resulting peptides were loaded into a mass spectrometer for fragmentation and sequencing. Sequencing results were used to identify the parent proteins via database searching. High performance duty cycle instruments can fragment hundreds of peptides in a single LC-MS/MS experiment. However, a prolactinoma, even from microdissected sample, contains thousands of tryptic peptides. At a given LC elution time, multiple coeluting peptides would quickly overwhelm other MS/MS acquisition speed of duty cycle instruments. In order to identify proteins from a complex mixture with a dynamic range of at least $10^{5}$ [9], it is crucial to develop technologies with extremely good resolving power and extraordinary sensitivity. It is obvious that these challenging tasks will not be achieved with a single analytical technique but with a combination of different separation and detection techniques.

As shotgun proteomics could generate such a large number of protein identifications via high-throughput 2D separation, we combined a 2D peptide-level separation performed by coupling strong cation exchange (SCX) with reverse phase (RP) plus SDS-PAGE protein prefraction to increase dynamic range and proteome coverage for bottom-up shotgun proteomics $[10,11]$.

In our recently published study we have reported a novel method for immuno-LCM in frozen sections of prolactinomas [12]. Microdissected prolactin cells were solubilized followed by protein separation on SDSPAGE gel. The gel slices were then digested and fractions of the resulting peptides were separated by 2DnanoLC/MS and characterized by tandem mass spectrometry [13]. All MS/MS spectrums were searched by SEQUEST against the human International Protein
Index (IPI human, version 3.45 fasta with 71983 entries) database to provide a profile of prolactinoma proteome. A proteome consisting of 2243 proteins was thereby acquired. Compared with previous pituitary adenoma proteome research [2], our proteome contains more than twenty times the number of proteins identified by an initial 2-DE map of extracts from a pituitary adenoma. Categories of the proteome include low-abundance proteins, membrane proteins, cyclin dependent kinases (CDK) and phosphoproteins.

\section{Results}

\section{Identification and characterization of prolactinoma}

\section{proteome}

Since one shortcoming of LCM is the number of pure cells for proteomic analysis was limited, only 100,000 cells were used in this work. Thus, separation steps were accordingly limited to reduce the sample loss. Proteins from this small number of cells were fractionated by SDS-PAGE first and the resolved protein gels were then cut into five sections according to several distinct protein bands observed within this gel (Fig. 1). The five sections cut from the SDS-PAGE gave the optimal results in terms of the detection sensitivity and the number of proteins identified.

Although some proteins were identified from more than one gel section, each of the five gel sections provided a large number of unique protein identifications. In this process, the peptide fragmentation pattern was matched to the peptides constructed from the theoretical human International Protein Index (IPI) database. A less than $5 \%$ false positive rate was estimated through the reverse database search (reverse the protein sequences in the human protein database). Such stringent criteria in our experiment would eliminate most peptides that would falsely increase the number of identified proteins (data not shown).

The matched peptide sequence analyzed by $2 \mathrm{D}$ nanoLC/MS was identified based on the fragmentation pattern (MS/MS) as well as mass accuracy of peptide molecular weight (within $10 \mathrm{ppm}$ ). From the digested peptides of the five gel slices, 122807 MS/MS spectrums were acquired and these data were used for SEQUESTbased database searches. The results from the five gel slices were combined as shown in Table 1; 28784 peptides including 115 for $5^{+}$ions, 1373 for $4^{+}$ions, 5972 for $3^{+}$ions and 21328 for $2^{+}$ions were submitted, and after removal of redundant proteins, 2249 proteins were finally identified. To our best knowledge, after eliminating six keratin proteins from skin or hair [2], the 2243 identified proteins represent the largest database of human pituitary to date(Additional file 1). Among these identified 2243 proteins, 1802 proteins were identified with at least two unique peptides representing 


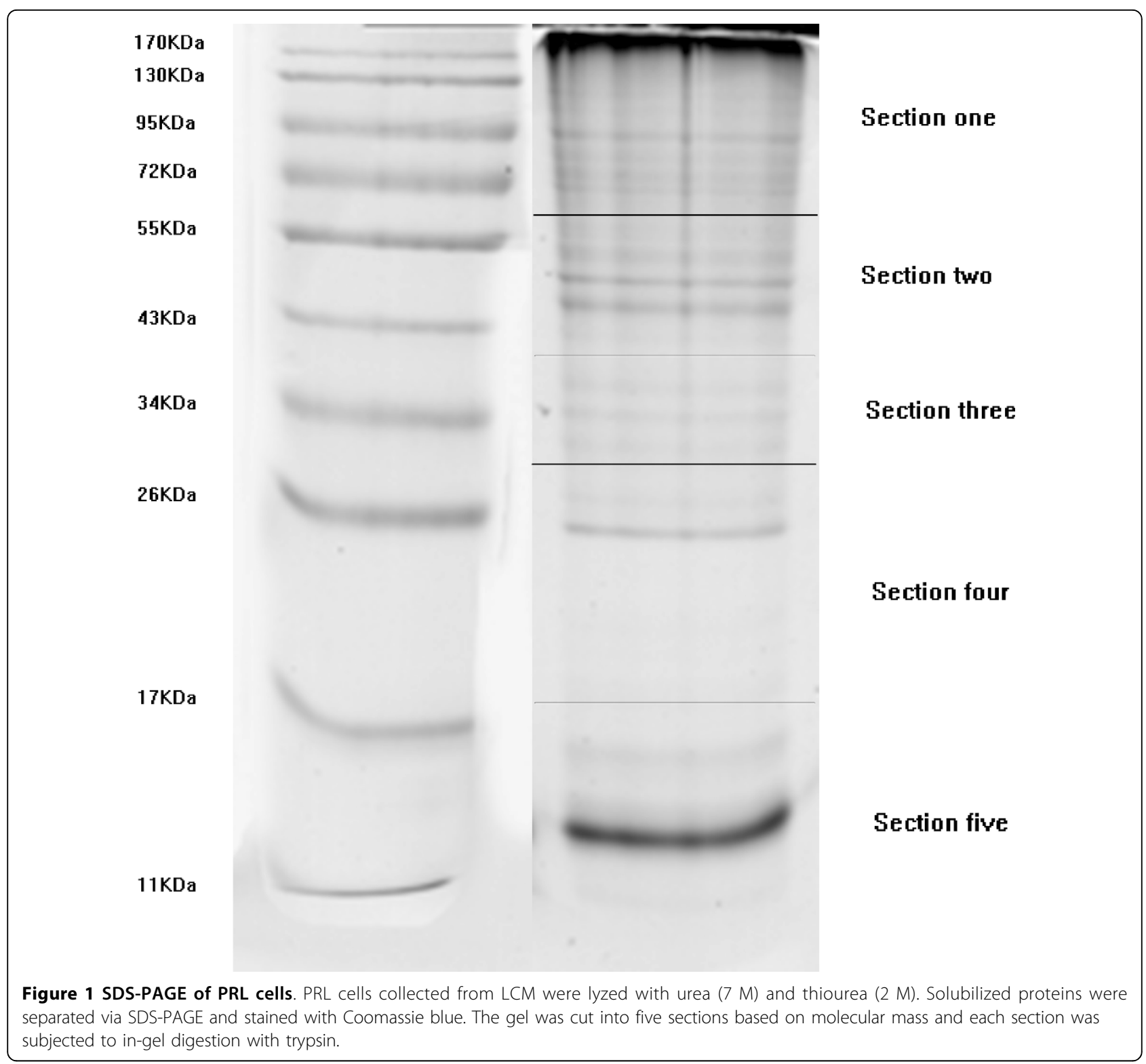

identifications of high probability. Cellular distribution of these identified proteins (as a percentage) was analyzed using a bioinformatic analysis tool-The Database for Annotation, Visualization and Integrated by Discovery [14] (DAVID 2009, Version 6) in Fig. 2.

\section{Discussion}

\section{Prolactinoma proteome by immuno-laser capture} microdissection

The global analysis of prolactinoma protein expression complements genomics analysis and may provide further insight into post-translational modifications affecting cellular function. The pituitary adenoma represents a complex heterogeneous mixture of cells including prolactin (PRL), endothelial cells, fibroblasts, and other stromal cells. Since Emmert-Buck MR et al [15] introduced LCM in 1996, this technique has been widely used to isolate specific cell types from mixture tissues for biomedical research especially for proteomic analysis [16-19]. Although this proteomic technique has been widely used with regard to different aspects of neurological diseases [20], there are few data available about proteomic analysis of human pituitary adenoma [2,21-24]. Therefore, in two earlier reviews about pituitary adenoma research Lloyd RV and Xianquan Zhan pointed out that LCM is a proposed and perspective method for pituitary adenoma proteomic analysis $[16,25]$. One research about normal pituitary by immuno-LCM had proved it a valuable technique for RNA analysis [26]. Our group has recently 
Table 1 Number of proteins identified in each gel section

\begin{tabular}{lccccc}
\hline Section number & Section 1 & Section 2 & Section 3 & Section 4 & Section 5 \\
\hline Number of protein & 747 & 805 & 769 & 672 & 346 \\
Protein matched $\geq 2$ peptides & 608 & 662 & 647 & 546 & 265 \\
\hline
\end{tabular}

demonstrated a novel method to acquire human pure prolactin cells for proteome analysis by immuno-LCM [12]. In this study we used SDS-PAGE combined with 2D-nanoLC-MS/MS strategies for proteome study to identify a total of 2243 unique proteins in prolactin cells. To our knowledge, this is the most comprehensive proteomic analysis of human pituitary adenoma to date.

Our previous experiments showed that TritonX-100 concentration for immunostaining was optimal at $0.2 \%$ for $4 \mathrm{~min}$ by extracting the lipid proteins from the adenoma cell surface [12]. Since hematoxylin [27] and IHC [28] stained tissues have been successfully employed with mass spectrometry, in order to test the compatibility of the pretreatment of $0.2 \%$ TritionX-100 solution with mass spectrometry, protein recovery from prolactinoma sections without treatment was directly compared with that from sections processed with the pretreatment of TrtionX-100, and no significant differences in protein recovery were observed between the two protocols (data not shown). The results demonstrated that the pretreament of $0.2 \%$ TrtionX-100 for 4 min did not affect proteomic analysis. In addition, the novel pretreatment provided improved morphological discrimination of prolactin cells for successful and easy LCM.
A comparison between two pituitary adenoma proteomes In an earlier pituitary adenoma proteome research by 2$\mathrm{DE}$ [2], the authors identified 111 proteins. Most of the 2-DE-separated spots were distributed in the area of $\mathrm{pH}$ 4-8 and mass $20-80 \mathrm{kDa}$. The mean MW of the proteome was $41.8 \mathrm{kDa}$, and the highest $\mathrm{MW}$ protein was "complement C3 precursor (fragment)" which had a 187.1 kDa MW and the lowest MW protein was "Myosin light chain alkali. Smooth muscle isoform" with a 6.5 $\mathrm{kDa}$ MW. The mean pI was 6.13 , and the highest $\mathrm{pI}$ protein was "RAB GDP dissociation inhibitor beta" which had a $9.8 \mathrm{pI}$ and the lowest pI protein was "Myosin light chain alkali" with a $4.38 \mathrm{pI}$ respectively. For the 39 LC-ESI MS/MS characterized proteins, the number of matched peptides ranged from 2 to 18 . The sequence coverage of these MS/MS data ranged from $7 \%$ to $56 \%$. While for the 96 MALDI characterized proteins, the number of matched peptides ranged from 4 to 19. The sequence coverage of these PMF data ranged from $7 \%$ $73 \%$.

Most of the identified proteins (70\%) MW in our research theoretically distributed between $20 \mathrm{kDa}$ and $100 \mathrm{kDa}$ (mean MW = $75.3 \mathrm{kDa}$ ). Nevertheless, there were still some proteins with an extremely low or high MW in our database. Thirteen proteins with MW $<10$

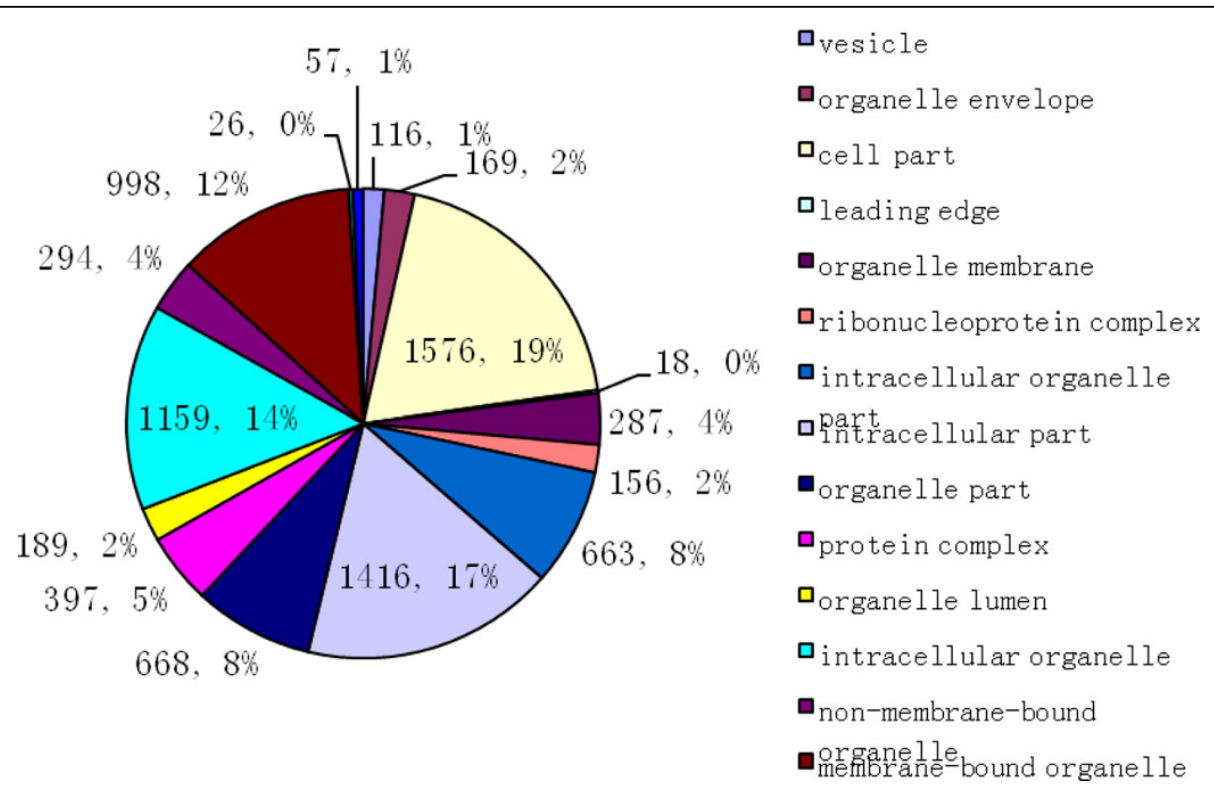

Figure 2 Categories of identified proteins in prolactinomas by cell components. The distribution of enrolled proteins in DAVID 2009 was $16 \%$ of cell part, $15 \%$ of intracellular part, $15 \%$ of intracellular, $12 \%$ of vesicle, $4 \%$ of protein complex and other 11 fractions according to cell components. 
$\mathrm{kDa}$ were identified; the smallest protein is the "upregulated skeletal muscle growth protein 5" (IPI 00063903.5) which has a theoretical MW of $6457 \mathrm{Da}$ (identified from gel section 5). A total of 143 proteins with MW of $>200 \mathrm{kDa}$ were identified; the largest protein identified in this work was "isoform of titin" (identified from protein section 1) which has a theoretical MW of 3805759 (IPI 00023283.3). The pI range of the proteome was between 3.93 and 12.05 (mean pI = 6.94), among which $16.7 \%$ of proteins were high basic proteins with pI greater than 9. The lowest and the highest pI protein were "isoform 1 of acidic leucine-rich nuclear phosphoprotein 32 family member B” (IPI 00007423.1) in section $2(\mathrm{pI}=3.93)$ and "isoform 1 of serine/arginine repetive matrix protein 2 (IPI 00782992.3) in section 4 $(\mathrm{pI}=12.05)$. Those proteins either with extreme molecular weights or pIs can be rarely detected by traditional 2-DE analysis of pituitary adenoma. In this new pituitary adenoma proteome, the number of matched peptides ranged from 1 to 128 . The sequence coverage of these MS/MS data ranged from $0.1 \%-87 \%$. (Table 2 ). The smallest sequence coverage in our research was quite lower than that of Zhan's results. There are many more high MW proteins identified in our report with only two or more peptides were matched to these proteins. However, low sequence coverage these proteins have, these proteins were identified with a high probability.

Using SDS-LC-MS/MS, Tomazella et al [29] identified 251 total cellular proteins from resting human neutrophils, that is more than ten times of proteins identified by an initial proteome analysis of human neutrophils and almost five times of proteins identified by the first 2-DE map of extracts of rat polymorphonuclear leukocytes. With SDS-2D-nanoLC-MS/MS in this research, the total number of identified proteins was substantially increased to 2243 and there are 79 in common between the two proteomes (Fig. 3). This might be explained with: (i) any proteome carried out by the present proteomic technology is only part of the "whole" proteome. There were differences in any different proteomes even they were from the same sample and MS; (ii) transmembrane proteins and Less abundant proteins were not easily extracted or identified in 2-DE studies either due to their hydrophobicity and aggregation during IEF, or low abundance [30]; (iii) In fact, many of the spots detected in the gels were actually variations of the products of post-translationally modified proteins [31] that were not usually detected by shotgun sequencing and thus can be a limiting factor of the shotgun approach; (iv) Pituitary adenomas were divided into six types according to the hormone secreted (GH,PRL,ACTH, TSH,LH,FSH) and each type of adenoma has its unique protein expression characters. Our proteome was from the pure prolactin cells of prolactinomas by immunoLCM while the other proteome by Xianquan Zhan was from the whole non-functional adenoma tissues [2], which may be the main reason for the difference.

In our experience, 2-DE identified and revealed relative distribution of more abundant proteins whereas LCESI-MS/MS identified less abundant proteins and hydrophobic proteins not amenable to detection by 2DE. After the immuno-LCM procedure, cells were lyzed and fractionated by molecular weight differences using SDS-PAGE, because SDS-PAGE was not only an effective pre-fractionation method [32], but also provided approximate molecular weight information for identified proteins [33]. One previously described immunostaining method for proteomics was based on immunogold detection and involved very short incubation times (5 min) and very high antibody titers (1/25-1/5) [34]. Such extreme ICH conditions have several potential drawbacks. In many cases, especially when using polyclonal antibodies, the background staining could be very high. In contrast to previously reported studies, we have demonstrated the membrane-mounted sections pretreatment of the frozen prolatinoma sections with $0.2 \%$ Triton $\mathrm{X}-100$ with a less drastic modifications to conventional IHC staining protocols was highly compatible with 2D-LC shot gun proteomic studies. The results obtained from this research clearly proved the capability of 2D-nano LC-MS/MS tandem mass spectrometry for the separation and identification of complex peptide samples compared with traditional 2-DE methods. Although some differences existed, both proteomes complemented each other and contributed to the elucidation of the mechanisms of prolactinoma.

Bioinformatics of the prolactinoma proteome

The protein biological process and functional categories provided an overview of the human pituitary adenoma tissue proteome based on the known or postulated

Table 2 Quality comparison of pituitary proteome by 2-DE and 2D-nanoLC/MS Table 2 indicated the quality comparison between the two pituitary adenoma proteomes on the number of matched peptides, matched peptides ratios, the percentage sequence coverage, $\mathrm{pl}$ range, MW range, mean $\mathrm{pl}$ and mean $\mathrm{MW}$.

\begin{tabular}{cccccccc}
\hline Methods & Number & Matched peptides & Sequence coverage & Mean pl & pl range & Mean MW (KDa) & MW range \\
\hline MS/MS & 39 & $2-18$ & $7-56 \%$ & 6.13 & $4.4-9.4$ & 41.8 & $12.1-180.7$ \\
PMF & 96 & $4-19$ & $7-73 \%$ & & & & 75.3 \\
MS/MS & 2249 & $1-128$ & $0.1-87 \%$ & 6.95 & $3.9-12.1$ & $6.5-380.6$ \\
\hline
\end{tabular}




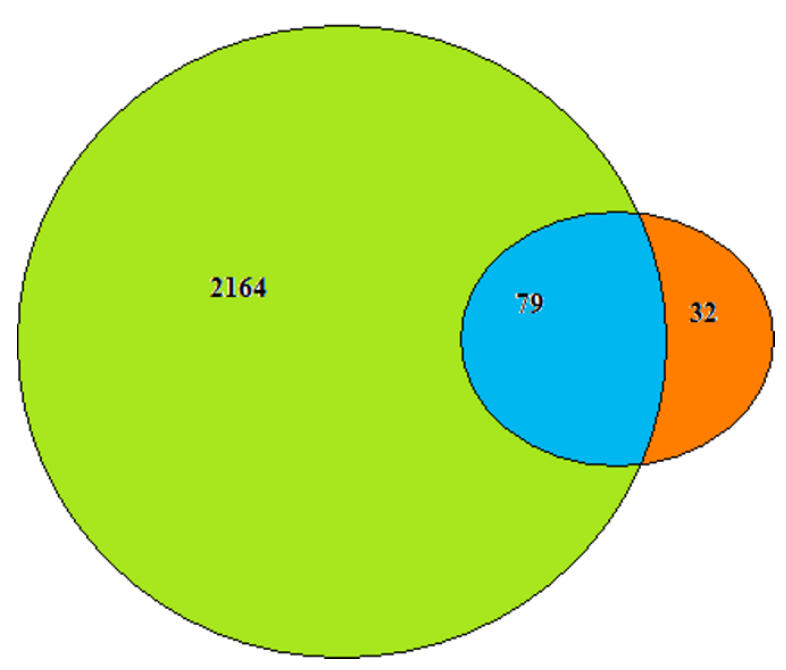

Figure 3 Protein overlaps of two proteomes. Total proteins are indicated for each proteome with two circles; subsets in common (in blue) are indicated within the diagram. It indicates that most proteins identified in 2-DE (in brown) are overlapped with what extracted from the prolactinomas by immuno-LCM (in green)

functions of the identified protein. Analysis of the proteome with DAVID revealed a notable identification of proteins participating in pituitary hormones, cellular signals, biosynthetic process, cellular metabolic process, cell development, response to endogenous stimulus, transportation, etc. Such functional groups are in agreement with pituitary biology in previous research [35-38]. The full classification of the proteins according to their biological functions is demonstrated in the pie chart in Fig. 4. Among the identified proteome, 2164 proteins that are potentially relevant to the biological process of proteome not yet been described in any of the papers researching pituitary adenomas cited above. Many proteins play complex biological roles, so in our research the total number of all subgroups was larger than that of the whole proteome. Our data suggests that SDSPAGE protein prefraction coupled with $2 \mathrm{D}$-nanoLC/MS peptide separations was still required to maximize the separation capacity to meet the challenge of the complexity of the prolactinoma proteome.

Several functionally important proteins pertinent to biological action of the prolactinoma were identified in this database which had been widely investigated in different aspects of pituitary adenoma.

Cyclin proteins: Cyclins and cyclin dependent kinases (CDK) (Isoform 1 of CDK Substrate, cyclin G-associated kinase and isoform 1 of calcyclin-binding protein were identified in the proteome database) are essential for cell cycle regulation in eukaryotes. Active cyclin-CDK complexes drive cells through cell cycle phases by phosphorylating the protein substrates that are essential for the transition to the next phase [39]. Several researches have found that prolactinomas significantly express cyclin gene and some cyclin genes may be a marker for invasion of prolactinomas and may also be related to tumor recurrence [40].

G-type cyclins (G1 and G2): G-type cyclins seem to participate in G2-M arrest in response to DNA damage [41]. G-type cyclins bind to GAK that is a serine/threonine cyclin G-associated kinase involved in epidermal growth factor receptor signaling [42]. G-type cyclins are targets of p53 and seem to be involved in the ATMp53-Mdm2 pathway [43].

The 14-3-3 family of proteins identified in the list had a further significance. The 14-3-3 (Ywha or 3-monooxygenase/tryptophan 5-monooxygenase activation protein) family consists of highly conserved, approximately 30 $\mathrm{kDa}$ acidic proteins that form homodimers or heterodimers [44]. In mammals, up to seven homologous isoforms of this kind of proteins have been described ( $\beta \gamma$ $\delta \varepsilon \zeta \eta \theta$ ) [45] (14-3-3 protein $\theta / \delta, 14-3-3$ protein $\varepsilon$, isoform long of 14-3-3 protein $\beta / \alpha, 14-3-3$ protein $\eta$, 14-33 protein $\gamma$ and 14-3-3 protein $\theta$ were detected in this research). The 14-3-3 family members mediate signal transduction by binding to phosphoserine-containing proteins. It interacts with $\mathrm{CDC}^{25}$ (cell division cyclin ${ }^{25}$ ) phosphatases, RAF1 and $\mathrm{p}^{27}$ proteins, suggesting its role in diverse biochemical activities related to signal transduction, such as cell division and regulation. All isoforms of 14-3-3 proteins recognize two high affinity phosphorylation dependent 14-3-3 binding motifs: $\mathrm{R}(\mathrm{S} /$ $\mathrm{X}) \mathrm{XpSXP}$ (mode 1) and RXXXpSXP (mode 2) where $\mathrm{pS}$ is a phosphoserine. 14-3-3 plays a role in the regulation of various cellular signaling events [46]: (i) change the ability of target protein to interact with other partners; (ii) modify the cellular localization of target protein; (iii) bridge two target proteins; (iv) change the activity of the target protein; and (v) protect their target protein. A recent research has been shown that 14-3-3 is able to act as a sub-cellular localization modifier for several phosphorylated proteins [47].

The $\mathrm{p}^{27}$ protein (IPI 00010860.1) belongs to the large family of cyclin-dependent kinase inhibitors (CDK1). The $\mathrm{p}^{27}$ protein regulates the progression of the cell cycle from the G1 to the $S$ phase. The levels of $\mathrm{p}^{27}$ protein in much malignant neoplasm are lower than those in normal tissues, suggesting that $\mathrm{p}^{27}$ may act as a suppressor and has a prognostic significance [48]. $\mathrm{P}^{27}$ protein has been identified to cause pituitary adenomas $[49,50]$. The very low levels of $\mathrm{p}^{27}$, both native and Thrphosphorylated, were seen in pituitary carcinoma [51]. In addition, recurrent pituitary adenomas show significantly lower $\mathrm{p}^{27}$ expression levels (47\%) than non-recurrent tumors (67.4\%) [52]. In one recent research, the molecular analysis of human pituitary neoplasm has 


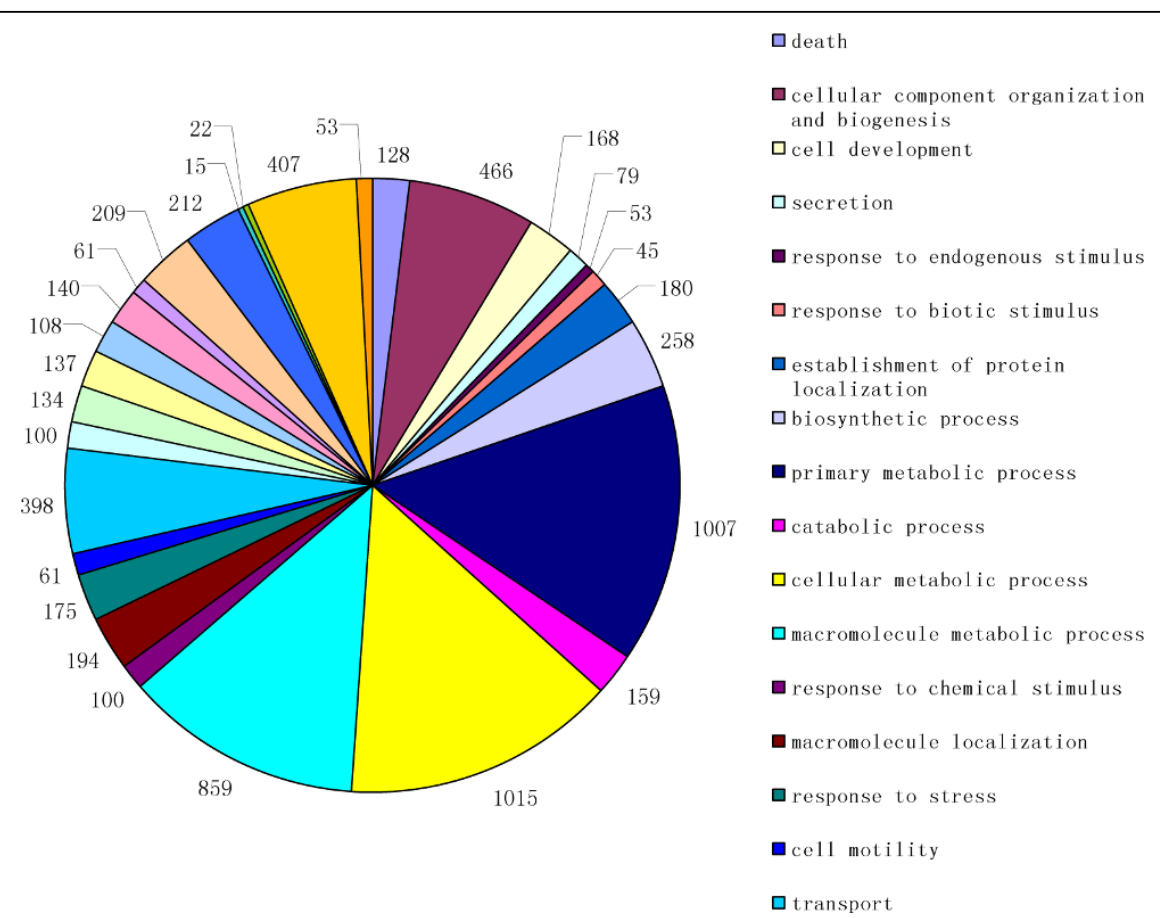

Figure 4 Categories of identified proteins in prolactinomas by biological process. Proteins in the proteome participate in pituitary hormones, cellular signals, biosynthetic process, cellular metabolic process, cell development, response to endogenous stimulus, transportation, etc

corroborated that the cell cycle inhibitor $\mathrm{p}^{27} \mathrm{Kip} 1$ deregulation is significantly implicated in pituitary tumorigenesis. In particular, proteins involved in cyclin-dependent kinase regulation or the $\mathrm{pRb}$ pathway are altered in nearly all human pituitary tumors [53].

\section{Limitations}

A pooled sample for proteomic profile analysis would represent a more comprehensive proteome of prolactinomas, but just because the mixture of many samples, the concentration of some protein would be too low to be detected by mass spectrometry and thus the integrity of the proteome was affected. Our team's next research would focus on the label-free comparative proteomic research, each prolactinoma sample will be analyzed by shotgun proteomics to produce mass spectral peak intensities and spectral counts, and the relative intensities of sequence ion fragment peaks within an MS/MS spectrum will be compared by statistics to get the differential proteins, and at the same time, an enlarged prolatinoma proteome will be obtained.

Though low density Triton X-100 had been proved to have no obvious affect on proteomic analysis [54], the pretreatment of TritonX-100 to improve the intensity of positive prolactin cells in LCM will definitely resulted in the loss of some proteins in cell membrane. The paraffin embodied pituitary adenomas sections need no Triton
$\mathrm{X}-100$ treatment during the IHC for LCM which might be another potential bank for further pituitary adenoma proteomic research. Our team had finished the experiment to get prolactin cells by LCM from paraffin embodied pituitary adenoma samples and the proteins number was nearly equal to that from frozen samples (data not shown).

\section{Conclusions}

In the present study, the proteome database of prolactinomas demonstrated that immuno-LCM coupled with 2D-nanoLC/MS mass spectrometry, should enable the analysis of protein expression profiles in defined group of prolactin cells, allowing us to extend the present proteome research to a wide range of other cell types of pituitary adenomas. This enlarged proteome will serve as a more comprehensive complement of understanding of previous pituitary adenoma proteome researches and will also provide a basis for label-free comparative proteomics to find the key cellular events of pituitary tumorigenesis in our future researches.

\section{Materials and methods}

Immuno-laser capture microdissection of prolactinomas

This study was performed under approval of the ethics committee of Huashan Hospital, Fudan University and informed consents were received from each patient. 
Eleven prolactinomas (5 males and 6 females) were collected during operations and cut approximately $3 \mathrm{~mm}$ in diameter for the subsequent frozen sections. Eightmicrometer sections on membrane-mounted slide (Microdissect $\mathrm{GmbH}$, Germany) were collected in the cryostat (Leica CM 1900, Germany) and immediately fixed in $100 \%$ ethanol for $15 \mathrm{~min}$; the sections were incubated in $0.2 \%$ Triton X-100 with Tris-Buffered Saline (TBS) for $4 \mathrm{~min}$ and then incubated at 1:300 dilution of primary anti-rabbit polyclonal prolactin antibody (Dako Cytomation, Copenhagen, Denmark) in the TBS solution for $30 \mathrm{~min}$ in a humid chamber, and then were washed twice for $3 \mathrm{~min}$ each in TBS. Afterwards, all sections were incubated with biotinylated "Universal" secondary antibody (Dako Cytomation Copenhagen, Denmark) for $20 \mathrm{~min}$ at room temperature. Finally, all sections were developed with diaminobenzidine (Dako Copenhagen, Denmark) for 1 to 2 min and counterstained with hematoxylin (Sigma Diagnostics, St. Louis, MO) and the sections were ready for LCM. A Varitas ${ }^{\mathrm{TM}}$ Arcturus LCM, combined with IR/UV system (Arcturus Molecular Devices, CA, USA), provide a narrow ultraviolet laser beam to "draw around" and cut out the cells of interest by photo volatilization $(20 \times)$. A cap would be placed on the tissue after the UV laser cut the desired area. The IR laser would tack the polymer to collect the desired cells. Laser cut parameters were: spot size $=4$ $\mu \mathrm{m}$, power $=80 \mathrm{~mW}$, pulse duration $=15 \mathrm{~ms}$. Time between pulses $=400 \mathrm{~ms}$. After a successful immunoLCM, thirty $8 \mu \mathrm{m}$ prolactinoma sections from eleven prolatinomas provided an approximately $6.0 \mathrm{~mm}^{2}$ surface area which was equal to 100,000 prolactin cells for the subsequent shotgun proteomic analysis.

\section{Cell lysis and SDS-PAGE gel protein separation}

Lysis buffer, containing urea (7 M) and thiourea (2 M), was added to a $0.5 \mathrm{ml}$ Eppendorf tube connected to the LCM cap. Captured cells were solubilized by a series of $20 \mathrm{~ms}$ sonication bursts, followed by a $20 \mathrm{~s}$ ice cooling, which was repeated five times. The entire extract $(\sim 40$ $\mu \mathrm{l})$ was loaded on a gel (SDS-PAGE, $4 \%-12 \%$ gradient) to separate proteins by molecular weight (MW) [13]. The MWs of the proteins were estimated by a comparison with the migration of standard proteins. This plot yielded a straight line; the MWs of the unknown proteins were determined by this plot, using the mobility calculated from the migration of the protein spot. After staining with Coomassie blue, the gel was cut into five individual sections with molecular mass ranges. Each section was further minced into small pieces (approximately $0.5 \mathrm{~mm}^{2}$ ) and subjected to destaining cycles of gel dehydration with $\mathrm{ACN}$ and rehydration with $\mathrm{NH}_{4} \mathrm{HCO}_{3}$ buffer $(0.1 \mathrm{M}, \mathrm{pH} 8.0)$ in order to remove the Coomassie stain. This procedure was repeated up to three times until no visible Coomassie stain remained.
The in-gel proteins were subsequently digested with sequence level trypsin reagent $(250 \mu \mathrm{l} ; 8 \mathrm{ng} / \mu \mathrm{l}$ trypsin in $25 \mathrm{mM} \mathrm{NH}_{4} \mathrm{HCO}_{3}, \mathrm{pH} 8.0$ ). The trypsin concentration was based upon an estimate of approximately 3-6 $\mu \mathrm{g}$ protein per gel section and adjusted if necessary. The solution was then replaced by $25 \mathrm{mM} \mathrm{NH}_{4} \mathrm{HCO}_{3}$ to cover the gel pieces (100-200 $\mu \mathrm{l})$ and incubated overnight at $37^{\circ} \mathrm{C}$. If needed, additional ammonium bicarbonate buffer would be added to completely cover the gel pieces. After digestion, the supernatant of each tube was transferred to another Eppendorf tube. To extract residual peptides, the gel pieces were sonicated for $20 \mathrm{~min}$ at $37^{\circ} \mathrm{C}$ in a solution of $60 \% \mathrm{ACN} / 0.5 \% \mathrm{TFA}$. The extraction was repeated twice. The extracts combined with the primary supernatant were dried in a vacuum centrifuge for further separation by 2D-nanoLC/MS.

\section{Automated 2D LC-ESI-MS/MS separation and identification}

All the extracted peptides of protein bands from SDSPAGE maps were desalted using a $1.3 \mathrm{ml} \mathrm{C18}$ solid phase extraction column (Sep-Pak ${ }^{\oplus}$ Cartridge, Waters Corporation, Milford, USA). The dried peptides then were resuspended in loading buffer ( $5 \mathrm{mM}$ Ammonium formate containing 5\%ACN, pH 3.0), separated and analyzed by $2 \mathrm{D}$ strong cation-exchange (SCX)/plus reversed-phase (RP) nano-scale liquid chromatography/ mass spectrometry. The experiments were performed on a Nano Aquity UPLC system (Waters Corporation, Milford, USA) connected to an LTQ-Orbitrap XL mass spectrometer (Thermo Electron Corporation, Bremen, Germany) equipped with an online nano-electrospray ion source (Michrom Bioresources, Auburn, USA).

A $180 \mu \mathrm{m} \times 2.4 \mathrm{~cm}$ SCX column (Waters Corporation, Milford, USA) packed with a $5 \mu \mathrm{m}$ polysulfoethyla spartamide (PolyLC, Columbia, MD, USA) was used for the first dimension of separation. To recover hydrophobic peptides still retained on the SCX column after a conventional salt step gradient, an RP step gradient from $15 \%$ to $50 \%$ acetonitrile $(\mathrm{ACN})$ was applied to the SCX column [55].

A $9 \mu \mathrm{l}$ plug was injected each time to form the step gradients. The buffers used to form the gradients were prepared from a $1 \mathrm{M}$ NH4FA stock solution, $\mathrm{pH} 3.20$. The buffers used for the conventional salt gradient (5$500 \mathrm{mM}$ ) contained $5 \% \mathrm{ACN}$, while the buffers prepared to form the RP step gradient (10\%-50\% ACN) all contained $500 \mathrm{mM}$ NH4FA. The organic solvent gradient was carried out following the salt gradient. The plugs were loaded onto the SCX column at a $4 \mu \mathrm{l} / \mathrm{min}$ flow rate for $4 \mathrm{~min}$, with a steps as following:(a): $5 \mathrm{mM}$ and 5\%ACN, (b) $100 \mathrm{mM}$ and 5\%ACN,(c): $200 \mathrm{mM}$ and5\% $\mathrm{ACN},(\mathrm{d}): 250 \mathrm{mM}$ and $5 \% \mathrm{ACN},(\mathrm{e}): 300 \mathrm{mM}$ and $5 \%$ $\mathrm{ACN},(\mathrm{f}): 400 \mathrm{mM}$ and $5 \% \mathrm{ACN}(\mathrm{g}): 500 \mathrm{mM}$ and $5 \%$ ACN, (h): $500 \mathrm{mM}$ and 15\% ACN, (i): $500 \mathrm{mM}$ and $30 \%$ 
ACN,(j): $500 \mathrm{mM}$ and 50\% ACN. At last, $1 \mathrm{M}$ Ammonium formate (NH4FA) was used to clean the SCX column twice. The eluted peptides were captured by a trap column (Waters Corporation, Milford, USA) while salts were diverted to waste. The trap column $(2 \mathrm{~cm} \times 180$ $\mu \mathrm{m})$ was packed with a $5 \mu \mathrm{m}$ Symmetry ${ }^{\circ} \mathrm{C} 18$ material (Waters Corporation, Milford, USA). The RP analytical column $(20 \mathrm{~cm} \times 75 \mu \mathrm{m})$ was packed with a $1.7 \mu \mathrm{m}$ Bridged Ethyl Hybrid (BEH) C18 material (Waters Corporation, Milford, USA), and was used for the second dimension separation.

The peptides loaded on the RP analytical column were eluted with a three-step linear gradient. Starting from $5 \% \mathrm{~B}$ to $45 \% \mathrm{~B}$ in $40 \mathrm{~min}$ (A: water with $0.1 \%$ formic acid; B: ACN with $0.1 \%$ formic acid), increased to $80 \% \mathrm{~B}$ in $3 \mathrm{~min}$, and then to $5 \% \mathrm{~B}$ in $2 \mathrm{~min}$. The column was re-equilibrated at initial conditions for $15 \mathrm{~min}$. The column flow rate was maintained at $300 \mathrm{nl} / \mathrm{min}$ and column temperature was maintained at $35^{\circ} \mathrm{C}$. The $1.1 \mathrm{kV}$ voltage electrospray versus the inlet of the mass spectrometer was used. LTQ-Orbitrap XL mass spectrometer was operated in the data-dependent mode to switch automatically between MS and MS/MS acquisition. Fullscan MS spectras with two microscans (m/z 300-1800) were acquired in the Orbitrap with a mass resolution of 60,000 at $\mathrm{m} / \mathrm{z} 400$, followed by ten sequential LTQ-MS/ MS scans. Dynamic exclusion was used with two repeated counts, 10 s repeated duration, and 60s exclusion duration. For MS/MS, precursor ions were activated using $35 \%$ normalized collision energy at the default activation $\mathrm{q}$ of 0.25 .

\section{Peptide Sequence and Data Interpretation}

Peptides ion eluted in salt gradient were identified by accurate molecular weight as a precursor ion and the product-ion spectrum was compared with the theoretical human protein index database after collision-induced dissociation (CID) of the precursor ion. All MS/MS spectrums were searched by SEQUEST (V28, revision 12, Thermo Electron Corporation) against the human International Protein Index (IPI) database. To reduce false positive identification results, a decoy database containing the reverse sequences was appended to the database. The searching parameters were set up as follows: two missed cleavages partial trypsin were considered, the variable modification was oxidation of methionine, the peptide mass tolerance was $10 \mathrm{ppm}$, and the fragment ion tolerance was $1 \mathrm{Da}$. Trans Proteomic Pipeline software (revision 4.0 Institute of Systems Biology, Seattle, WA) was then utilized to identify proteins based upon corresponding peptide sequences with more than $95 \%$ confidence. The peptides results were filtered by peptide prophet [56] with a $P$-value over 0.05 then a protein prophet [57] probability of 0.95 was used for the protein identification.
Additional file 1: Prolactinoma proteome database. Microsoft Excel spreadsheet (XLS format) containing the proteome database for prolactin cells isolated from prolactinomas by immuno-LCM.

Click here for file

[http://www.biomedcentral.com/content/supplementary/1477-5956-8-2S1.XLS ]

\section{Abbreviations}

2D: two-dimensional; IHC: Immunohistochemistry; 2-DE: two-dimensional electrophoresis; MS: mass spectrometry; SDS-PAGE: Sodium dodecylsulfate polyacrylamide gel electrophoresis; MALDI-TOF: Matrix-assisted laser desorption/ionizationtime of flight mass spectrometry; ESI: Electrospray ionization; TBS: Tris-Buffered Saline; ACN: acetonitrile; SCX: strong cationexchange; RP: reversed-phase; LTQ: linear trap quadrupole; LCM: laser capture microdissection; PRL: prolactin; nanoLC/MS: nano-scale liquid chromatography/mass spectrometry; PMF: Peptide Mass Fingerprinting; pl: isoelectric Point; MW: molecular weight

\section{Acknowledgements}

The authors gratefully acknowledge financial grants (to Jianhong Zhu) from (30870805, 90919002, 2007CB947902, 2009CB941100, 06dj14001, 08dj1400503, 075407070) the National Nature Science Foundation, Major State Basic Research Program and Shanghai Science Foundation.

\section{Author details}

${ }^{1}$ Department of Neurosurgery, Shandong Provincial hospital affiliated to Shandong University, Jinan, 250021, China. ${ }^{2}$ Shanghai Neurosurgical Center, Department of Neurosurgery, Huashan Hospital, Shanghai Medical College, Fudan University, Shanghai, 200040, China. ${ }^{3}$ Department of Chemistry, Fudan University, Institutes for Biomedical Sciences, Fudan University, Shanghai, 200433, China. ${ }^{4}$ Department of Gastroenterology, Shandong Provincial Qianfoshan Hospital affiliated to Shandong University, Jinan, 250014, China ${ }^{5}$ National Key Lab for Medical Neurobiology, Institutes of Brain Sciences, Fudan University, Shanghai, 200032, China.

\section{Authors' contributions}

YL performed LCM, data analysis and drafted the manuscript. JW provided the pituitary adenoma tissues, partly designed the experiment and participated in the writing of the manuscript. GY performed trypsin digestion and protein identification by mass spectrometry. $\mathrm{RH}$ contributed to the bioinformatics analysis. LC optimized SDS-PAGE. QP took part in experimental design, protein identification by MS and revision of the final manuscript. DZ assisted in immunohistochemistry and contributed to the final manuscript. JZ participated in experimental design, data analysis, coordination and revision of the final version of the manuscript. All authors read and approved the final manuscript.

\section{Competing interests}

The authors declare that they have no competing interests.

Received: 20 September 2009

Accepted: 29 January 2010 Published: 29 January 2010

\section{References}

1. Ezzat $\mathrm{S}, \mathrm{Asa} \mathrm{SL}$, Couldwell WT, Barr CE, Dodge WE, Vance $M L$, McCutcheon IE: The prevalence of pituitary adenomas: A systematic review. Cancer 2006, 101(3):613-619.

2. Zhan $X$, Desiderio DM: A reference map of a human pituitary adenoma proteome. Proteomics 2003, 3:699-713.

3. Desiderio DM, Zhan X: The human pituitary proteome: the characterization of differentially expressed proteins in an adenoma compared to a control. Cell Mol Biol 2003, 49:689-712.

4. Evans CO, Moreno CS, Zhan X, McCabe MT, Vertino PM, Desiderio DM Oyesiku NM: Molecular pathogenesis of human prolactinomas identified by gene expression profiling, RT-qPCR, and proteomic analyses. Pituitary 2008, 11(3):231-245.

5. Schutze K, Lahr G: Identification of expressed genes by laser-mediated manipulation of single cells. Nat Biotechnol 1998, 16(8):737-742. 
6. Fend F, Emmert-Buck MR, Chuaqui R, Cole K, Lee J, Liotta LA, Raffeld M: Immuno-LCM: Laser Capture Microdissection of Immunostained Frozen Sections for mRNA Analysis. Am J Pathol 1999, 154(1):61-66.

7. Klose J, Kobalz U: Two-dimensional electrophoresis of proteins: An updated protocol and implications for a functional analysis of the genome. Electrophoresis 1995, 16(6):1034-1059.

8. Link AJ, Eng J, Schieltz DM, Carmack E, Mize GJ, Morris DR, Garvik BM Yates JR: Direct analysis of protein complexes using mass spectrometry. Nat Biotechnol 1999, 17(7):676-682.

9. Rabilloud T: Two-dimensional gel electrophoresis in proteomics: old, old fashioned, but it still climbs up the mountains. Proteomics 2002, 2(1):3-10.

10. Fournier ML, Gilmore JM, Martin-Brown SA, Washburn MP: Multidimensional separations-based shotgun proteomics. Chem Rev 2007, 107(8):3654-3686.

11. Dowell JA, Frost DC, Zhang J, Li L: Comparison of Two-Dimensional Fractionation Techniques for Shotgun. Anal Chem 2008, 80(17):6715-6723.

12. Liu Y, Wu J, Liu S, Zhuang D, Wang Y, Shou X, Zhu J: Immuno-laser capture microdissection of frozen prolactinoma sections to prepare proteomic samples. Colloids and Surfaces B: Biointerfaces 2009, 71(2):187-193.

13. Lu Q, Murugesan N, Macdonald JA, Wu SL, Pachter JS, Hancock WS: Analysis of mouse brain microvascular endothelium using immuno-laser capture microdissection coupled to a hybrid linear ion trap with Fourier transform-mass spectrometry proteomics platform. Electrophoresis 2008, 12: 2689-2695.

14. Dennis G Jr, Sherman BT, Hosack DA, Yang J, Gao W, Lane HC, Lempicki RA: DAVID: Database for Annotation, Visualization, and Integrated Discovery. Genome Biol 2003, 4(5):P3.

15. Emmert-Buck MR, Bonner RF, Smith PD, Chuaqui RF, Zhuang Z, Goldstein SR, Weiss RA, Liotta LA: Laser capture microdissection. Science 1996, 274(5289):998-1001.

16. Lloyd RV: Advances in pituitary pathology: use of novel techniques. Front Horm Res 2004, 32:146-147.

17. Espina V, Wulfkuhle JD, Calvert VS, VanMeter A, Zhou W, Coukos G, Geho DH, Petricoin EF, Liotta LA: Laser capture microdissection. Nat Protoc 2006, 1(2):586-603.

18. Mustafa D, Kros JM, Luider T: Combining laser capture microdissection and proteomics techniques. Methods Mol Biol 2008, 428:159-178.

19. Domazet B, Maclennan GT, Lopez-Beltran A, Montironi R, Cheng L: Laser capture microdissection in the genomic and proteomic era: targeting the genetic basis of cancer. Int J Clin Exp Pathol 2008, 1(6):475-488.

20. Morrison RS, Kinoshita Y, Johnson MD, Uo T, Ho JT, McBee JK, Conrads TP, Veenstra TD: Proteomic analysis in the neurosciences. Mol Cell Proteomics 2002, 1:553-560.

21. Zhan X, Evans CO, Oyesiku NM, Desiderio DM: Proteomics and transcriptomics analyses of secretagogin down-regulation in human non-functional pituitary adenomas. Pituitary 2003, 6(4):189-202.

22. Moreno CS, Evans CO, Zhan X, Okor M, Desiderio DM, Oyesiku NM: Novel molecular signaling and classification of human clinically nonfunctional pituitary adenomas identified by gene expression profiling and proteomic analyses. Cancer Res 2005, 65(22):10214-10222.

23. Asa SL, Ezzat S: Genetics and proteomics of pituitary tumors. Endocrine 2005, 28(1):43-47.

24. Liu ZX, Liu YS, Fang WH, Chen W, Li C, Xiao ZQ: Establishment of differential expression profiles from invasive and non-invasive pituitary adenomas. J Cent South Univ (Med Sci) 2009, 34(07):569-575.

25. Zhan X, Desiderio DM: Comparative proteomics analysis of human pituitary adenomas: Current status and future perspectives. Mass Spectrometry Reviews 2005, 24(6):783-813.

26. Jin L, Tsumanuma I, Ruebel KH, Bayliss JM, Lloyd RV: Analysis of homogeneous populations of anterior pituitary folliculostellate cells by laser capture microdissection and reverse transcription-polymerase chain reaction. Endocrinology 2001, 142(5):1703-1709.

27. Zang L, Palmer TD, Hancock WS, Sgroi DC, Karger BL: Proteomic analysis of ductal carcinoma of the breast using laser capture microdissection, LCMS, and ${ }^{16} \mathrm{O} /{ }^{18} \mathrm{O}$ isotopic labeling. J Proteome Res 2004, 3(3):604-612.

28. Moulédous L, Hunt S, Harcourt R, Harry JL, Williams KL, Gutstein HB: Proteomic analysis of immunostained, laser-capture microdissected brain samples. Electrophoresis 2003, 24(1-2):296-302.
29. Tomazella GG, da Silva I, Laure HJ, Rosa JC, Chammas R, Wiker HG, de Souza GA, Greene L: Proteomic analysis of total cellular proteins of human neutrophils. Proteome Sci 2009, 7(1):32.

30. Corthals GL, Wasinger VC, Hochstrasser DF, Sanchez JC: The dynamic range of protein expression: A challenge for proteomic research. Electrophoresis 2000, 21:1104-1115.

31. Fountoulakis M, Tsangaris G, Oh JE, Maris A, Lubec G: Protein profile of the HeLa cell line. J Chromatogr A 2004, 1038:247-265.

32. Allen MJ, Howard JA, Lilley KS, Wilson WH: Proteomic analysis of the EhV86 virion. Proteome Sci 2008, 6-11.

33. de Godoy LM, Olsen JV, Cox J, Nielsen ML, Hubner NC, Fröhlich F, Walther TC, Mann M: Comprehensive mass-spectrometry-based proteome quantification of haploid versus diploid yeast. Nature 2008, 455(7217):1251-1254.

34. Craven RA, NTotty N, Harnden P, Selby PJ, Banks RE: Laser Capture Microdissection and Two-Dimensional Polyacrylamide Gel Electrophoresis. Am J Pathol 2002, 160:815-822.

35. Vidal S, Kovacs K, Horvath E, Rotondo F, Kuroki T, Lloyd RV, Scheithauer BW: Topoisomerase II alpha expression in pituitary adenomas and carcinomas: relationship to tumor behavior. Mod Pathol 2002, 15(11):1205-1212.

36. Korbonits M, Chahal HS, Kaltsas G, Jordan S, Urmanova Y, Khalimova Z, Harris PE, Farrell WE, Claret FX, Grossman AB: Expression of phosphorylated $\mathrm{p}^{27}(\mathrm{Kip} 1)$ protein and Jun activation domain-binding protein 1 in human pituitary tumors. J Clin Endocrinol Metab 2002, 87:2635-2643.

37. Thapar K, Scheithauer B, Kovacs K, Pernicone PJ, Laws ER Jr: p53 expression in pituitary adenomas and carcinomas: correlation with invasiveness and tumor growth fractions. Neurosurgery 1996, 38:765-769.

38. Thapar K, Kovacs K, Scheithauer B, Stefa-neanu L, Horvath E, Pernicone JP, Murray D, Laws RE Jr: Proliferative activity and invasiveness among pituitary adenomas and carcinomas: an analysis using the MIB-1 antibody. Neurosurgery 1996, 38:99-107.

39. Jordan S, Lidhar K, Korbonits M, Lowe DG, Grossman AB: Cyclin D and cyclin $\mathrm{E}$ expression in normal and adenomatous pituitary. Eur $\mathrm{J}$ Endocrinol 2000, 143(1):R1-6.

40. Turner HE, Nagy Z, Sullivan N, Esiri MM, Wass JA: Expression analysis of cyclins in pituitary adenomas and the normal pituitary gland. Clin Endocrinol (Oxf) 2000, 53(3):337-344.

41. Kimura SH, Ikawa M, Ito A, Okabe M, Nojima H: Cyclin G1 is involved in $\mathrm{G} 2 / \mathrm{M}$ arrest in response to DNA damage and in growth control after damage recovery. Oncogene 2001, 20(25):3290-3300.

42. Zhang L, Gjoerup O, Roberts TM: The serine/threonine kinase cyclin Gassociated kinase regulates epidermal growth factor receptor signaling. Proc Natl Acad Sci USA 2004, 101(28):10296-10301.

43. Chen X: Cyclin G: a regulator of the p53-Mdm2 network. Dev Cell 2002, 2(5):518-519.

44. Chaudhri M, Scarabel M, Aitken A: Mammalian and yeast 14-3-3 isoforms form distinct patterns of dimers in vivo. Biochem Biophys Res Commun 2003, 300(3):679-685.

45. Dougherty MK, Morrison DK: Unlocking the code of 14-3-3. J Cell Sci 2004, 117(Pt 10):1875-1884.

46. Takahashi Y: The 14-3-3 proteins: gene, gene expression, and function. Neurochem Res 2003, 28(8):1265-1273.

47. Gouraud SS, Yao ST, Heesom KJ, Paton JF, Murphy D: 14-3-3 proteins within the hypothalamic-neurohypophyseal system of the osmotically stressed rat: transcriptomic and proteomic studies. J Neuroendocrinol 2007, 19(11):913-922.

48. Lloyd RV, Erickson LA, Jin L, Kulig E, Qian X, Cheville JC, Scheithauer BW: p27kip1: a multifunctional cyclin-dependent kinase inhibitor with prognostic significance in human cancers. Am J Pathol 1999, 154(2):313-323.

49. Jacks T, Fazeli A, Schmitt EM, Bronson RT, Goodell MA, Weinberg RA: Effects of an Rb mutation in the mouse. Nature 1992, 359(6393):295-300.

50. Nakayama K, Ishida N, Shirane M, Inomata A, Inoue T, Shishido N, Horii I, Loh DY, Nakayama K: Mice lacking p27 (Kip1) display increased body size, multiple organ hyperplasia, retinal dysplasia, and pituitary tumors. Cell 1996, 85(5):707-720.

51. Korbonits M, Chahal HS, Kaltsas G, Jordan S, Urmanova Y, Khalimova Z, Harris PE, Farrell WE, Claret FX, Grossman AB: Expression of phosphorylated $\mathrm{p} 27$ (Kip1) protein and Jun activation domain-binding 
protein 1 in human pituitary tumors. $J$ Clin Endocrinol Metab 2002, 87(6):2635-2643.

52. Nakabayashi H, Sunada J, Hara M: Immunohistochemical analysis of cell cycle-related proteins, apoptosis, and proliferation in pituitary adenomas. J Histochem Cytochem 2001, 49(9):1193-1194.

53. Quereda V, Malumbres M: Cell cycle control of pituitary development and disease. J Mol Endocrinol 2009, 42(2):75-86.

54. Nakamura M, Sakurai Y, Takeda, Toda T: Comparative proteomics of flotillin-rich Triton X-100-insoluble lipid raft fractions of mitochondria and synaptosomes from mouse brain. J Electrophor 2005, 49(4):77-83.

55. Liu H, Finch JW, Luongo JA, Li GZ, Gebler JC: Development of an online two-dimensional nano-scale liquid chromatography/mass spectrometry method for improved chromatographic performance and hydrophobic peptide recovery. J Chromatogr A 2006, 1135(1):43-51.

56. Keller A, Nesvizhskii Al, Kolker E, Aebersold R: Empirical statistical model to estimate the accuracy of peptide identifications made by MS/MS and database search. Anal Chem 2002, 74(20):5383-5392.

57. Nesvizhskii Al, Keller A, Kolker E, Aebersold R: A statistical model for identifying proteins by tandem mass spectrometry. Anal Chem 2003, 75(17):4646-4658.

doi:10.1186/1477-5956-8-2

Cite this article as: Liu et al:: Proteomic analysis of prolactinoma cells by immuno-laser capture microdissection combined with online twodimensional nano-scale liquid chromatography/mass spectrometry. Proteome Science 2010 8:2.

\section{Submit your next manuscript to BioMed Central and take full advantage of:}

- Convenient online submission

- Thorough peer review

- No space constraints or color figure charges

- Immediate publication on acceptance

- Inclusion in PubMed, CAS, Scopus and Google Scholar

- Research which is freely available for redistribution

Submit your manuscript at www.biomedcentral.com/submit
Biomed Central 